\title{
KINETIC RELEASE STUDY OF DIABETES MELLITUS DRUG ENCAPSULATED ON CHITOSAN ALGINATE MATRIX
}

\author{
S. E. Cahyaningrum ${ }^{\bowtie}$, Amaria and A. M. Sholikhah \\ Department of Chemistry, Faculty of Mathematics and Natural Sciences \\ Universitas Negeri Surabaya, J1. Ketintang, Surabaya-60231, Indonesia \\ ${ }^{\square}$ Corresponding Author: saricahyaningrum@unesa.ac.id
}

\begin{abstract}
One way of the release control of the glibenclamide is the process of encapsulation using a blend of calcium alginate-chitosan polymer with the addition of tween 80 surfactants. The resulting microparticles were analyzed for encapsulation efficiency, dissolution test in gastric and artificial intestinal $\mathrm{pH}$ solutions, functional groups, and surface morphology. The encapsulation efficiency showed that the Tween 80 with a concentration of $4 \%$ can produce the highestencapsulation efficiency of $65,2568 \%$. The kinetic release of glibenclamide encapsulated on intestinal medium showed that the amount of glibenclamide dissolved in the gastric medium is lower than in the intestinal medium so that it can prevent gastric irritation by the mechanism of glibenclamide release through a combination of diffusion and erosion. The FT-IR spectra of the glibenclamide, alginate, chitosan, and glibenclamideencapsulated on the matrix showed that glibenclamide is only trapped physically in the alginatechitosan matrix. SEM test results show that the surface morphology of the glibenclamide is encapsulated smooth, porous small and there is no agglomeration.
\end{abstract}

Keywords: Diabetes Mellitus, Chitosan Alginate, Control Release System, Kinetic Release, Encapsulation.

RASĀYAN J. Chem., Vol. 14, No.2, 2021

\section{INTRODUCTION}

Encapsulation is a technique to protect a material by using a polymer as a coating. ${ }^{1}$ Encapsulation aims to increase the stability and solubility of a compound, control the release of active compounds, produce stable solid particles that are coated by certain coatings and minimize nutrient loss from a compound. ${ }^{2}$ Control release of active compounds can prevent the increase in the concentration of the drug in the digestive tract simultaneously to prevent irritation of the digestive tract, especially irritation in gastric ${ }^{3}$.Natural polymers are more often used as coatings because they are nontoxic, bioavailable, biocompatible and biodegradable. ${ }^{4,5}$ Some types of natural polymers that are often used as coatings in encapsulation techniques are gum guar ${ }^{6}$, alginate ${ }^{7}, \operatorname{chitosan}^{8}$, and albumin ${ }^{9}$. The difference in the type of coating and the amount of coating used will affect the efficiency of the encapsulation because it is related to the amount of active ingredient that is coated. ${ }^{10}$

In this research, chitosan and alginate will combine with cross-linked is $\mathrm{Ca}^{2+}$ ions for glibenclamide coating for a controlled release system. Chitosan is a polycation that is often used as a drug coating and is mucoadhesive, ${ }^{11}$ so that the absorption of active substances will increase. ${ }^{12}$ The amino group from chitosan, will react with polyanionics that have carboxylic groups, such as carboxymethylcellulose derived from alginate. ${ }^{13}$

Alginate is bioadhesive, but its bioadhesive properties are less appropriate when it meets the surface of the intestinal mucosa in oral drug delivery which causes less absorption. ${ }^{13}$ To maximize the absorption of alginate in the intestine, then it is necessary to add a cross-linking agent. The presence of divalent ions such as $\mathrm{Ca}^{2+}$, causes alginate to form ionic gelation caused by the formation of an eggbox the divalent metal ions combination with Mannuronate Gururate (MG) blocks in the polymer chain. ${ }^{14}$

Calcium alginate-chitosan is very suitable for coating the drug because it can increase the stability of the capsule, is mucoadhesive so that the capsule will last longer in the intestine and the absorption of active substances in the intestine becomes increased. ${ }^{11,15} \mathrm{~A}$ mixture of alginate-chitosan added with $\mathrm{Ca}^{2+}$ will form a polyelectrolyte complex through the carboxylic ion reaction of $\mathrm{Ca}$-alginate polyanion with amine 
RASĀYAN J. Chem.

Vol. 14 | No. 2 |1273-1280| April - June | 2021

ions from chitosan polycation to produce a stronger matrix which is characterized by the large value of the encapsulation efficiency. ${ }^{7}$

Alginate-chitosan has a weakness that is difficult to mix, so that must be added with a surfactant as an emulsifier to the alginate-chitosan mixture. Tween 80 is a nonionic surfactant with a value of HLB (Hydrophilyc Lipophilyc Balance) of 15 which tends to dissolve in water. ${ }^{16}$ Tween 80 can reduce the surface tension between the drug and the medium while forming micelles so that the drug can be carried by micelles and dissolve in the medium. At concentrations of $1-10 \%$ Tween 80 can act as a solubility enhancer. ${ }^{17}$

Glibenclamide is one of the most taken oral diabetes medications treating type two diabetes mellitus. ${ }^{18}$ The relatively short half-life of glibenclamide causes glibenclamide to be consumed by diabetics three times a day for a long period and allows greater toxic effects caused to the body. ${ }^{19}$ In addition, the uncontrolled release pattern of glibenclamide causes many active glibenclamide substances that are released in the gastric to irritate the gastric. The presence of glibenclamide encapsulation with calcium alginate-chitosan can control the release of active substances from glibenclamide so that the frequency of consumption of glibenclamide drugs can be reduced and the risk of toxic effects caused is smaller.

The encapsulation drugs have low toxicity because there can be used to improve the efficacy of therapeutic and to reduce the adverse effects, decrease the dose, and dosing frequency. ${ }^{20}$ The control release system of diabetes mellitus drugs is very important. This study will be investigated of the synthesis and characterization of the glibenclamide encapsulation process with a variation concentration of Tween 80. The glibenclamide encapsulated was evaluated of the characteristic, efficiency encapsulation and kinetic release mechanism.

\section{Material and Methods}

\section{EXPERIMENTAL}

Sodium alginate is isolated from brown algae was purchased from PT. MKR Chemical Ltd Semarang Indonesia; Chitosan was purchased from PT. Chitosindo Chitin Indonesia with a deacetylated degree is $85 \%$. Glibenclamide was obtained from PT. First Medipharma Indonesia. The other materials were used there are Calcium chloride, Tween $80, \mathrm{AgNO}_{3}$, Acetic acid, $\mathrm{KH}_{2} \mathrm{PO}_{4}, \mathrm{NaOH}$, Sodium Chloride and $\mathrm{HCl}$. The equipment utilized in this experiment was Spectrophotometer UV-Vis Shimadzu-1700 was for glibenclamide efficiency and dissolution analysis, Spectrophotometer Infra-Red (FTIR Perkin Elmer Frontier-89485) was for spectrum function group analysis, and SEM for analysis of morphology.

\section{Glibenclamide Encapsulation at Alginate-Chitosan Matrix}

A total of 1 gram of glibenclamide drug has been mashed, put in a $100 \mathrm{~mL}$ beaker, and added with $3 \mathrm{~mL}$ of $2 \%$ alginate solution, stirred using a glass mixer until homogeneous and no bubbles. Then the solution is dropped into a $0.15 \mathrm{M} \mathrm{CaCl}_{2}$ solution using a dropper pipette. The granules formed are left to stand in $\mathrm{CaCl}_{2}$ solution for 10 minutes, after which they are filtered and washed using distilled water to neutral $\mathrm{pH}$ and $\mathrm{Cl}$-free filtrate which can be tested by dripping $\mathrm{AgNO}_{3}$ solution in the filtrate. The granules formed were left to stand for 30 minutes, then immersed in Tween 80 solution with various concentrations $(0$, $1 \%, 2 \%, 3 \%$, and $5 \%$ ) and allowed to stand for 10 minutes. The granules are filtered and soaked in $0.1 \%$ chitosan solution for 10 minutes. After that, the solution is filtered, and the granules obtained are dried at room temperature. The glibenclamide encapsulated was characterized this functional group.

\section{Encapsulation Efficiency Test}

A total of $25 \mathrm{mg}$ of encapsulated glibenclamide was dissolved in $50 \mathrm{~mL}$ of buffer phosphate solution $\mathrm{pH}$ 7.4, stirred using a magnetic stirrer at room temperature until a homogeneous solution was obtained. The solution was analyzed using a UV-Vis spectrophotometer at $362 \mathrm{~nm}$.

\section{Kinetic Release Test}

Glibenclamide dissolution test encapsulated alginate-chitosan-Tween 80 was carried out on two media, namely the medium of gastric solution ( $\mathrm{pH}$ 1.2) and the medium of intestinal solution (pH 7.4) which was carried out for 60 minutes. Each $100 \mathrm{mg}$ of encapsulated glibenclamide is placed in a different container 
RASĀYAN J. Chem.

Vol. 14 | No. 2 |1273-1280| April - June | 2021

containing $100 \mathrm{~mL}$ of gastric and intestinal media solutions. Aliquots are taken at 10, 15, 20, 25, 30, 35, $40,45,50,55$ and 60 minutes as much as $10 \mathrm{~mL}$. Every $10 \mathrm{~mL}$ aliquot was taken, is replaced with a new solution of the same volume. Dissolution test sample solution is measured using a UV-Vis spectrophotometer with maximum wavelength so that the absorbance of the sample is obtained.

\section{Encapsulation of Glibenclamide}

\section{RESULTS AND DISCUSSION}

Glibenclamide will be coated by two alginate polymers and chitosan through the polyelectrolyte bond between alginate and chitosan ${ }^{11}$. The divalent ion $\mathrm{Ca}^{2+}$ will replace the $\mathrm{Na}^{+}$ion which crosses between the mannuronic acid group and the guluronic acid group from the Na-alginate which breaks off when the alginate is dissolved in aquadest and is characterized by the formation of white gel granules ${ }^{7}$. Alginate that is crosslinked with $\mathrm{Ca}^{2+}$ ions will interact with chitosan to form a second layer which increases its mechanical strength ${ }^{22}$. Calcium alginate-chitosan reaction can be observed in Fig.-1.

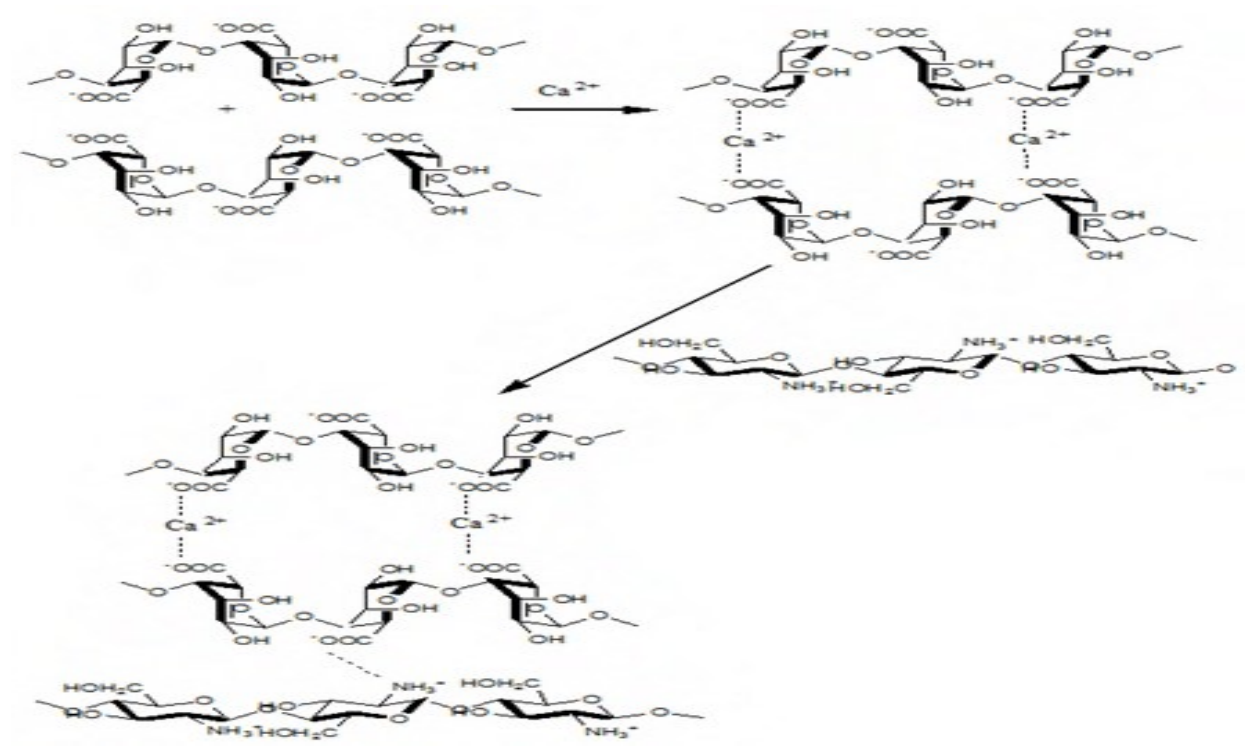

\section{Efficiency Encapsulation}

Fig.-1: Mechanism Interaction of Calcium-Alginat and Chitosan. ${ }^{21}$

The value of the encapsulation efficiency showed that the greatest levels of glibenclamide which is coated by calcium alginate-chitosan. The encapsulation efficiency test was carried out in a phosphate buffer medium of $\mathrm{pH} 7,4^{23}$. The results of wavelength optimization in the UV-Vis spectrophotometer obtained the maximum wavelength for glibenclamide in phosphate buffer solution $\mathrm{pH} 7,4$ at $203 \mathrm{~nm}$.

From the results of measurements of encapsulation efficiency, the addition of Tween 80 with a concentration of $4 \%$ obtained the highest value of the efficiency encapsulation is $65.2568 \%$ which can be observed in Fig.-2. The higher the Tween 80 concentration, the higher the value of the encapsulation efficiency produced but, there was a decrease in efficiency when using Tween 80 with a concentration of $5 \%$. This happens because the concentration of Tween 80 is above CMC (Critical Micell Concentration). When the concentration of Tween 80 is below the CMC, Tween 80 can reduce surface tension because micelles have not formed so that the stability of the droplets is better and can accelerate the dispersion system of the glibenclamide-alginate capsules. ${ }^{23}$ Tween 80 concentration under CMC can also reduce agglomeration between alginate-chitosan because a good layer is formed around the surface of the matrix so that the value of the efficiency of the encapsulation increases. When the Tween 80 concentration is above $\mathrm{CMC}$, Tween 80 is unable to make a layer around the surface of the matrix resulting in the possibility of agglomeration between alginate-chitosan can be formed so that the droplet stability becomes poor and inhibits the dispersion system of the glibenclamide-alginate capsules. ${ }^{7}$ 
RASĀYAN J. Chem.

Vol. 14 | No. 2 |1273-1280| April - June | 2021

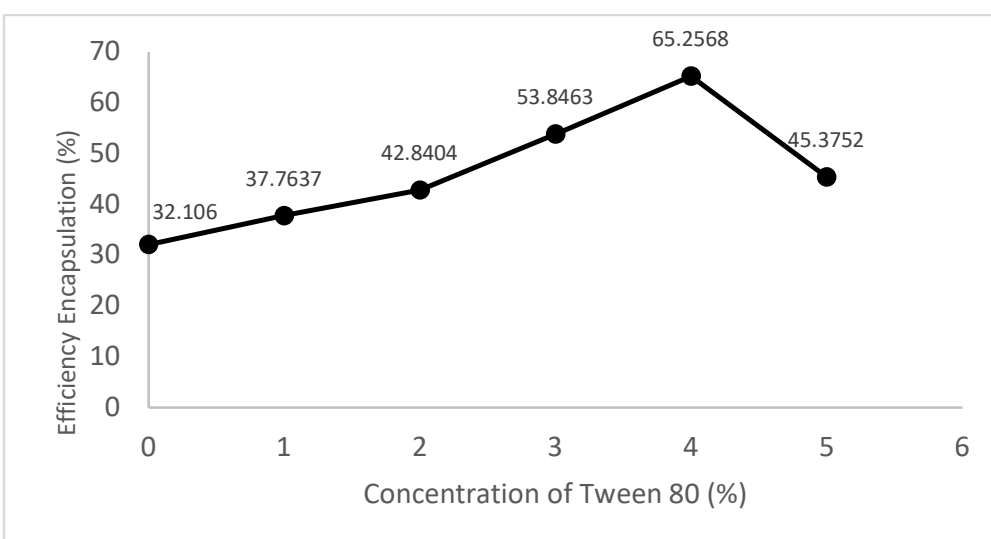

Fig.-2: Efficiency Encapsulation of Glibenclamide

\section{Kinetic Release Test}

Glibenclamide encapsulation using double coating calcium alginate-chitosan added with Tween 80 surfactant as an emulsifier can control the release of glibenclamide active substances in the gastric and intestinal medium because of the double coating effect. In the gastric medium, chitosan will dissolve, but the alginate does not dissolve so that the active ingredient glibenclamide remains coated in the alginate. When in the intestinal medium, calcium alginate will dissolve and cause the active substance glibenclamide to be released in the intestinal medium. The encapsulated gibenclamide dissolution test data results that can be observed in Figs. -3 and 4 are used to determine the mechanism release of glibenclamide active substances from the matrix. Some reaction kinetics models were used there are Korsmeyer-Peppas, Higuchi, zero and first order. The kinetics are assumed to follow the release pattern based on the regression equation from the relevant kinetics model. ${ }^{25}$ In addition, if the value of $n<0.5$ indicates that the mechanism of release of the active substance of the drug occurs by controlled diffusion, $\mathrm{n}>1$ indicates the mechanism of release of the active substance in an erosive manner and $0.5<\mathrm{n}<1$ indicates the mechanism of the combined release pattern between erosion and diffusion. ${ }^{6}$ The kinetic results of the release of glibenclamide active substances in the gastric and intestinal medium can be observed in the Tables-1 and 2. From Table-1 and 2 can be seen that the pattern of releasing the glibenclamide active substances in the gastric medium tends to follow the Korsmeyer-Peppas equation with a value of $0.43>n>0.73$, which shows the mechanism of diffusion and erosion. In the intestinal medium, the release of glibenclamide tends to follow the Higuchi equation with a value of $n>1$ indicating an erosion mechanism.

Table-1: Kinetic Release of Glibenclamide Encapsulated in Artificial Gastric medium

\begin{tabular}{c|c|c|c|c|c|c|c|c}
\hline \multirow{2}{*}{$\begin{array}{c}\text { Formula } \\
\text { Tween }\end{array}$} & \multicolumn{2}{|c|}{ Orde Nol } & \multicolumn{2}{c}{ Orde satu } & \multicolumn{2}{c}{ Higuchi } & \multicolumn{2}{c}{ Korsmmeyer-Peppas } \\
\cline { 2 - 9 } & $\mathrm{R}^{2}$ & $\mathrm{n}$ & $\mathrm{R}^{2}$ & $\mathrm{n}$ & $\mathrm{R}^{2}$ & $\mathrm{n}$ & $\mathrm{R}^{2}$ & $\mathrm{~N}$ \\
\hline $0 \%$ & 0.5313 & 0.1071 & 0.5242 & 0.0074 & 0.6398 & 1.3061 & 0.7505 & 0.5925 \\
\hline $1 \%$ & 0.5488 & 0.1337 & 0.5486 & 0.0051 & 0.6532 & 1.6212 & 0.754 & 0.3997 \\
\hline $2 \%$ & 0.5501 & 0.1632 & 0.4667 & 0.0089 & 0.663 & 1.9908 & 0.6933 & 0.7224 \\
\hline $3 \%$ & 0.3772 & 0.1183 & 0.3459 & 0.007 & 0.4909 & 1.4996 & 0.5696 & 0.5994 \\
\hline $4 \%$ & 0.6775 & 0.1151 & 0.6389 & 0.0061 & 0.7768 & 1.3693 & 0.8443 & 0.4686 \\
\hline $5 \%$ & 0.5714 & 0.0988 & 0.5661 & 0.0055 & 0.6794 & 1.1975 & 0.7864 & 0.4304 \\
\hline
\end{tabular}

Table-2: Kinetic Release of Glibenclamide Encapsulated in Artificial Intestinal Medium

\begin{tabular}{c|c|c|c|c|c|c|c|c}
\hline \multirow{2}{*}{$\begin{array}{c}\text { Formula } \\
\text { Tween }\end{array}$} & \multicolumn{2}{|c|}{ Orde Nol } & \multicolumn{2}{c|}{ Orde satu } & \multicolumn{2}{c|}{ Higuchi } & \multicolumn{2}{c}{ Korsmmeyer-Peppas } \\
\cline { 2 - 8 } & $\mathrm{R}^{2}$ & $\mathrm{~N}$ & $\mathrm{R}^{2}$ & $\mathrm{n}$ & $\mathrm{R}^{2}$ & $\mathrm{n}$ & $\mathrm{R}^{2}$ & $\mathrm{~N}$ \\
\hline $0 \%$ & 0.9716 & 2.5511 & 0.8691 & 0.0236 & 0.9787 & 30.077 & 0.9674 & 1.9045 \\
\hline $1 \%$ & 0.9302 & 2.6728 & 0.7844 & 0.0239 & 0.9613 & 31.917 & 0.9165 & 1.9724 \\
\hline $2 \%$ & 0.9468 & 2.0784 & 0.9285 & 0.0266 & 0.9244 & 24.125 & 0.9588 & 2.0678 \\
\hline $3 \%$ & 0.9622 & 1.6723 & 0.8504 & 0.0413 & 0.9492 & 19.511 & 0.9384 & 3.319 \\
\hline $4 \%$ & 0.9155 & 1.2912 & 0.7082 & 0.0262 & 0.9542 & 14.648 & 0.895 & 1.9682 \\
\hline $5 \%$ & 0.9588 & 2.055 & 0.9391 & 0.0294 & 0.9311 & 23.787 & 0.9848 & 2.307 \\
\hline
\end{tabular}


RASĀYAN J. Chem.

Vol. 14 | No. 2 |1273-1280| April - June | 2021

Chitosan can form a gel layer that has a viscosity in an acidic solution as in gastric medium which has a $\mathrm{pH}$ of 1.2. The dissolution media solution penetrates the matrix which causes the matrix to expand and form a gel. Chitosan will expand when interacting with the medium, forming pores that allow the solvent to enter the matrix so that the active drug substance is carried to the medium through a diffusion mechanism. Due to the nature of chitosan, which is soluble only in the acidic medium, the solvent that enters the matrix will increase and make the matrix saturated and cause an erosion process on the outer surface of the drug. This is what can reduce the presence of the matrix so that the active substance of the drug can be released from the preparation.

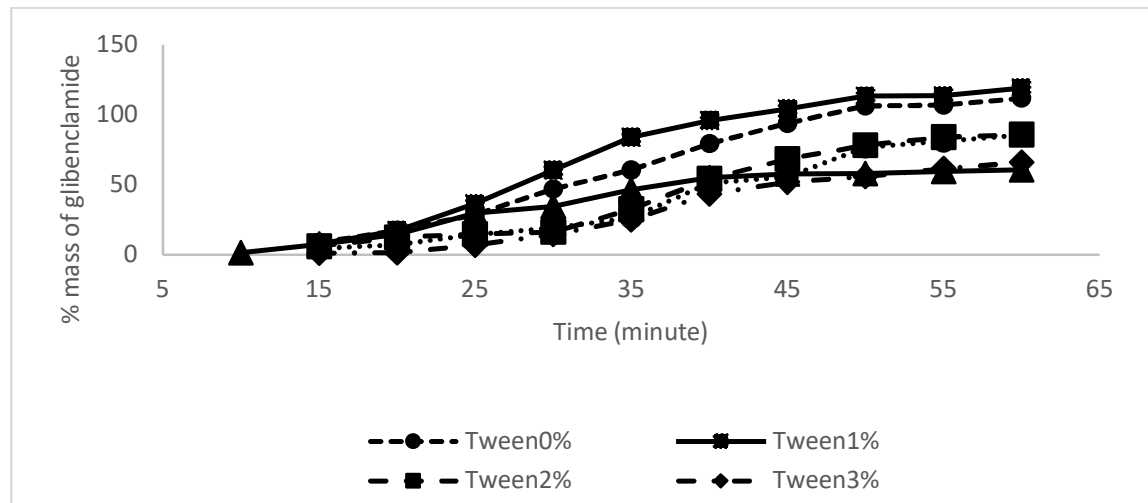

Fig.-3; The Result of Dissolutin Test Glibenklamid encapsulated with calcium alginate-chitosan in artificial Intestinal medium

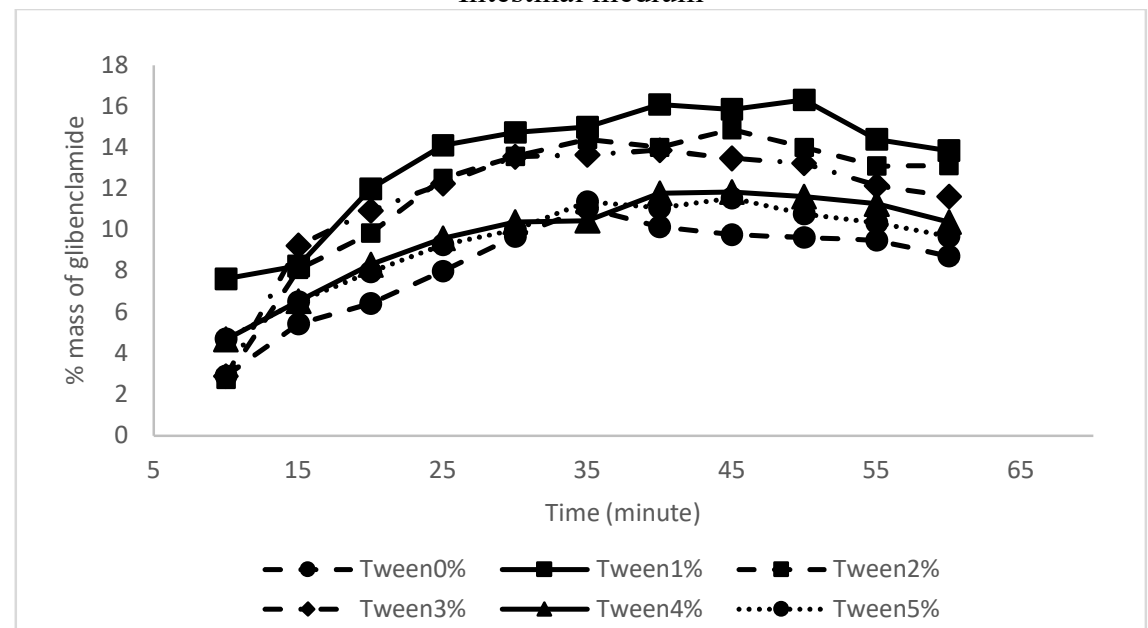

Fig.-4: The Result of Dissolutin test Glibenklamid encapsulated with calcium alginate- chitosan in artificial gastric

\section{Characteristic of Particle}

medium.

The FT-IR testing was carried out on calcium alginate-chitosan-encapsulated glibenclamide with the addition of $80-4 \%$ Tween compared to the FT-IR spectra of alginate, chitosan and pure glibenclamide which can be observed in Fig.-4. The presence of $\mathrm{CO}$ groups from carboxylates is also indicated by the peak of the carbohydrate peak. at $1297.81 \mathrm{~cm}^{-1}$ in low alginate spectra. ${ }^{24}$ This shows that the C-O group of many alginates has been bound with $\mathrm{Ca}^{2+}$ ions as a crosslinking agent for the carboxylic group ($\mathrm{COO}){ }^{26}$ Absorption in the region of $1419.84 \mathrm{~cm}^{-1}$ indicates that the COO-Ca polyelectrolyte was formed which originated from the -COO group in the alginate spectra in the region of $1406.40 \mathrm{~cm}^{-1}$ which binds to $\mathrm{Ca}^{2+}$ ions. In addition, the absorption in the region of $1522.94 \mathrm{~cm}^{-1}$ from the encapsulated glibenclamide spectra also showed the binding of carboxyl groups originating from alginate with amine groups from chitosan through $\mathrm{N}-\mathrm{O}$ bonds to form an alginate-chitosan polyelectrolyte. Insignificant spectral changes from alginate, chitosan, pure glibenclamide and glibenclamide encapsulated alginate- 
RASĀYAN J. Chem.

Vol. 14 | No. 2 |1273-1280| April - June | 2021

chitosan-Tween $80 \%$ showed that alginate-chitosan polyelectrolytes did not interact chemically with glibenclamide but only physically trapped glibenclamide

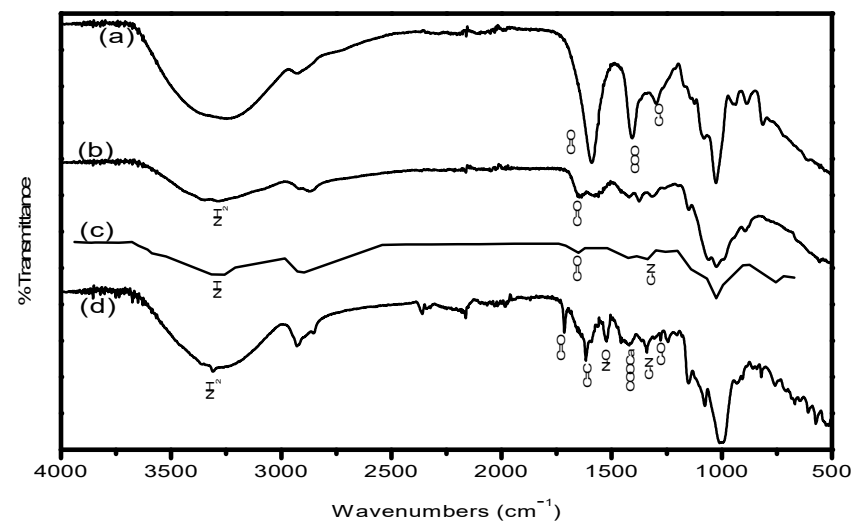

Fig.-5: FT-IR Spectrum of (a) Alginate, (b) Chitosan, (c) Pure Glibenclamide, and (d) Glibenclamide encapsulated with calcium alginate-Chitosan-Tween $804 \%$.

SEM test results with a magnification of $125 \mathrm{x}$ and $500 \mathrm{x}$ can be seen that the surface morphology of the glibenclamide is encapsulated smooth and there are no lumps or agglomeration on the surface. This can occur because of the addition of surfactant Tween 80 with a concentration of $4 \%$ acting as an alginate emulsifier with chitosan to prevent agglomeration between the two because it has one of the properties that are difficult to mix. Figure- 6 shows that when the drug dissolves in the body, the active drug substance will release through the pores of the drug matrix that is formed. The pattern of release through the pores of the matrix is what supports the diffusion release pattern in the physiological solution of gastric $\mathrm{pH} 1.2$.

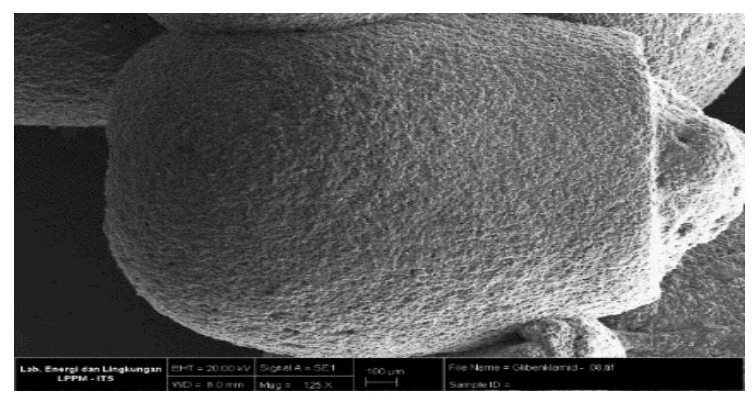

(a)

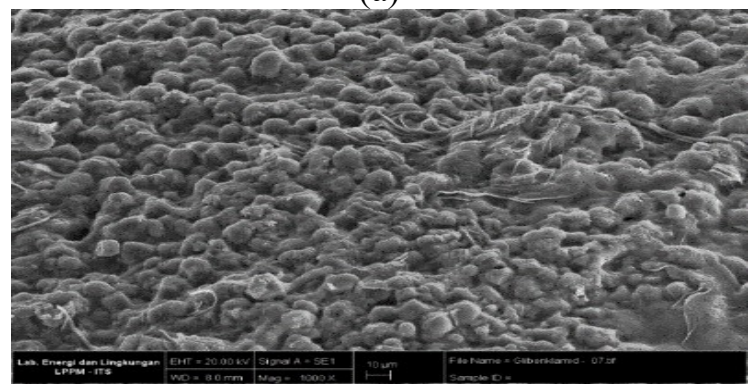

(c)

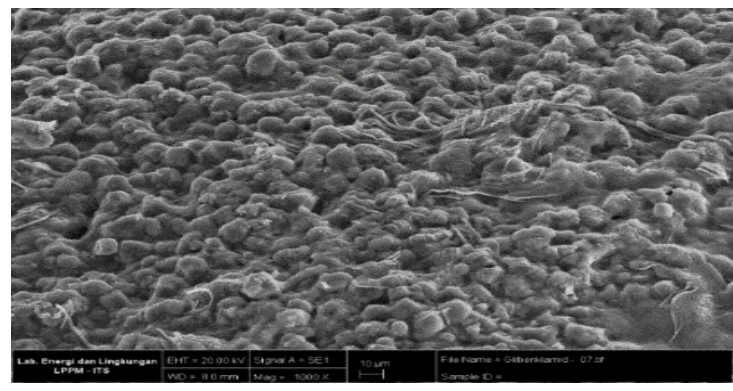

(b)

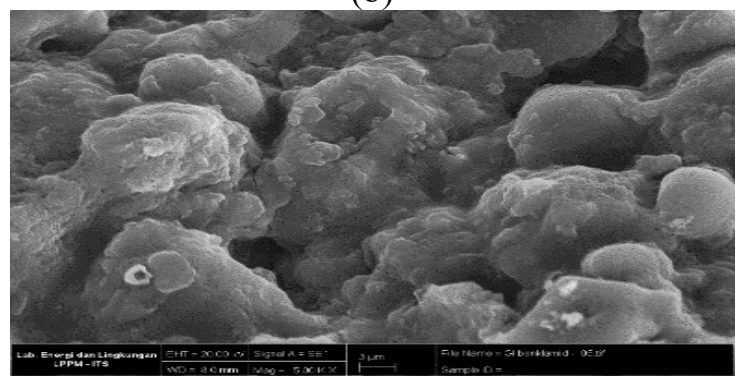

(d)

Fig.-6: SEM Image of Glibenclamide Encapsulated with calcium alginate-chitosan -Tween $804 \%$ in zoom (a) 125x, (b) $500 \mathrm{x}$, (c) $2000 \mathrm{x}$ dan (d) $5000 \mathrm{x}$.

\section{CONCLUSION}

Glibenclamid encapsulation using double calcium alginate-chitosan coating and the addition of tween 80 surfactants at an optimum concentration of $4 \%$ can control the release of glibenclamide in the body so 
RASĀYAN J. Chem.

Vol. 14 | No. 2 |1273-1280| April - June | 2021

that it can maximize the absorption of glibenclamide active substances in the body. Tween 80 at a concentration of $4 \%$ can increase the value of the encapsulation efficiency to $65.2568 \%$ because Tween 80 acts as an emulsifier that can reduce agglomeration between alginate and chitosan. The pattern of glibenclamide release encapsulated in the gastric medium follows the Korsmeyer Peppas equation with the mechanism of diffusion and erosion while the intestinal medium follows the Higuchi equation with the erosion mechanism. The insignificant changes in FT-IR spectra of alginate, chitosan, pure glibenclamide and glibenclamide encapsulated alginate-chitosan-Tween 80 4\% showed that alginatechitosan polyelectrolytes did not interact chemically with glibenclamide but only trapped glibenclamide physically $4 \%$. SEM test results can be seen that the surface morphology of the glibenclamide is encapsulated smooth, porous, small and there are no lumps or agglomeration.

\section{ACKNOWLEDGEMENT}

The authors wish thanks to DRPM funding for support this research with Penelitian Dasar Unggulan Perguruan Tinggi Programe 2020 with number contract: B/11638/UN38.9/LK.04.00/2020, Mei 42020.

\section{REFERENCES}

1. W. Krasaekoopt, B. Bhandari, and H. Deeth, International Dairy Journal, 13(3), 3(2003), DOI: $10.1016 /$ S0958-6946(02)00155-3

2. B. Khatun, N. Banik, A. Hussain, A. Ramteke and T. Maji, Journal of Microencapsulation, 35(5), 439(2018), DOI: 10.1080/02652048.2018.1524524

3. S. D. Deosarkar, R.T. Sawale, P. D. Tawde and T. M. Kalyankar, Russian Journal of Physical Chemistry A, 89, 232(2015), DOI:10.1134/S0036024415020077

4. A. Umakanthareddy, J. Sreeramulu and S. Punna, S., Research Journal of Pharmaceutical, Biological and Chemical Sciences, 3(2), 725 (2012).

5. S. A. Alavijeh, R. Shaddel and S. MahdiJafari, Food Hydrocoloids, 105, 105774(2020), DOI: $10.1016 /$ j.foodhyd.2020.105774G

6. P. Sabitha, J.V. Ratna, K. R. Reddy. International Journal of Chem Tech Research, 2(1), 88(2010)

7. J. Jayanudin, J. Rochmadi, M. Renaldia, P. Kemal, ALCHEMY Jurnal Penelitian Kimia, 13(2), 275 (2017)

8. B.P. Kumar1, I. S. Chandiran, and K. Narasimha, International Current Pharmaceutical Journal, 2(12), 196(2013)

9. N. V. N. Jyothi, P. M. Prasanna, S. N. Sakarkar, K. S. Prabha, P. S. Ramaiah, and G Y Srawan, Journal Microencapsulation, 27(3), 187(2010), DOI:10.3109/02652040903131301

10. S. Takka and G. Aybige, Journal An Official Journal of the American Association of Pharmaceutical Scientists, 11 (1), 460 (2010).

11. S. Arora and R. D. Budhiraja, Journal of Advanced Pharmaceutical Technology \& Research, 3(169) (2012), DOI: 10.4103/2231-4040.93555

12. T. Kumar, W.P. Manoj, P. Chandra, M.A. Sharma, and Kuriachan, Journal TrendsBiomaterials Artificial Organs, 18 (2), 198(2005)

13. P.R. Patil, S. Praveen, R. H. S. Rani, A. R. Paradkar, Journal An Official Journal of the American Association of Pharmaceutical Scientists, 2(2), 9(2005)

14. Y. Wu., W. Yang., C. Wang, J. Hu., and S. Fu. Internation Journal of Pharmauceutics, 35 (2), 235 (2005).

15. A. Behera, P. Srikanth, Y. M. Rao, and S. K. SahooImmunology, Endocrine \& Metabolic Agents in Medicinal Chemistry, 16(1), (2016), DOI: 10.2174/1871522216666160122224357

16. A. M. Mohsen, M. M. A.Samra and S. A. El Shebiney, Journal Drug Development and Industrial Pharmacy ,43(8), 1254 (2017), DOI:10.1080/03639045.2017.1310224

17. S. E. Cahyaningrum, N. Herdyastuti, W. Imroni and A. Sholikhah, Rasayan Journal of Chemistry, 13 (1), 389(2020), DOI:10.31788/RJC.2020.1315551

18. R. B. Kassab, and R. El-Hennamy, Egyptian Journal Basic and Applied Science, 4, 167(2017), DOI:10.1016/j.ejbas.2017.07.002

19. R. Khlibsuwan and T. Pongjanyakul, International Journal of Pharmaceutics, 535, 410(2018). 
RASĀYAN J. Chem.

Vol. 14 | No. 2 |1273-1280| April - June | 2021

20. R. Sanz. Beatriz Clares, M. Mallandrich, J. Carbó and A. C. Calpena, International Journal of Pharmaceutics, 535(1-2), 393(2018), DOI:10.1016/j.ijpharm.2017.11.027

21. S. E. Cahyaningrum, N. Herdyastuti, N. Qomariah, Indonesian Journal of Chemistry, 15(1), 16(2015), DOI:10.22146/ijc.21218

22. A. C. Friedli and I. R. Schlager, Journal of Chemical Education, 82(7), 1017(2005), DOI:10.1021/ed082p1017

23. L. Pachuau and B. Mazmumder, International Journal of Pharmatech, 4(3), 74(2009)

24. Jelita, B. Wirjosentono, Tamrin and L. Marpaung, Rasayan Journal of Chemitry, 12(3), 1157(2019), DOI:10.31788/RJC.2019.1235378

25. Muhardina, V. Putri Meutia Sari, Yuliani Aisyah, Sri Haryani and Said Ali Akbar, Rasayan Journal of Chemistry, 13(1), 240(2020), DOI:10.31788/RJC.2020.1315267

26. V. Muhardina, P. M. Sari, Y. Aisyah, S. Haryani and S. A. Akbar, Rasayan Journal of Chemistry, 13(1), 240(2020), DOI:10.31788/RJC.2020.1315569

[RJC-6218/2020] 